\title{
16. BACKSCATTER SEM IMAGERY OF FINE-GRAINED SEDIMENTS FROM SITE 671, LEG 110-PRELIMINARY RESULTS 1
}

\author{
David J. Prior ${ }^{2}$ and Jan H. Behrmann ${ }^{3}$
}

\begin{abstract}
Backscatter imagery, on the scanning electron microscope (SEM), has two major advantages over secondary electron imagery. It gives compositional information, and the planar, polished surfaces required are suitable for accurate and easy two-dimensional quantification of grain sizes, shapes and orientations. Generally backscatter imagery has insufficient spatial resolution for examination of the fine-grained matrix of muddy sediments. Previous workers have mostly been limited to secondary electron imagery of broken surfaces and its inherent restrictions. Here we describe specimen preparation and SEM operation procedures that allow resolution of the fine-grained matrix of sediments.

For high-resolution backscatterred electron imagery of any specimen a highly polished specimen surface is required. Careful preparation of polished surfaces of sediment specimens from Hole 671B of Leg 110 of the Ocean Drilling Program, combined with an optimization of SEM operating conditions, has given a spatial resolution of 200 to $300 \mathrm{~nm}$ and, in some specimens, better than $100 \mathrm{~nm}$. Best resolution is obtained by using a relatively high accelerating voltage ( $30 \mathrm{kV}$ here) and short working distances $(<7 \mathrm{~mm}$ here). The resolution obtained is good enough to allow quantification of clay and clast grain sizes and orientations, while backscatter intensities combined with semi-quantitative X-ray analysis is a powerful technique for identification of different clay phases.

A study of the microfabric of the décollement zone of Hole 671B indicates that there is no preferred alignment of clays or clasts. Thus, deformation must have occurred by independent particuate flow at high pore-fluid pressures. The "scaly fabric" of the décollement zone is defined by fractures that postdate and are unrelated to the microfabric.
\end{abstract}

\section{INTRODUCTION}

Optical examination of fine-grained sediments using ultrathin sections (Potter et al., 1980), is severely limited. The grain size of many fine-grained sediments approaches the wavelength of light, and good optical resolution of these grains will never be possible. Thus, to increase the spatial resolution, electron optical methods must be adopted.

Transmission electron microscopy (TEM) is a powerful tool that not only allows resolution of grains in the sub-micrometer range, but also their internal structure and grain boundary relationships (Smart and Tovey, 1982). However, specimen preparation for TEM is time consuming, and the specimen area that can be examined is very limited.

Scanning electron microscopy (SEM) allows rapid examination of specimens at magnifications between about $20 \times$ and several tens of thousands. There are two main image types obtainable with the SEM (see Lloyd, 1985; 1987 for summary); secondary electron (SE) images and backscattered electron (BSE) images. SE imaging of broken specimen surfaces has been used very sucessfully to examine fine-grained sediments (Smart and Tovey, 1982). Fabrics and grain morphologies are clearly visible in SE images of specimens from the Barbados accretionary complex (Moore et al., 1986). However, such images are of little use for quantitative microfabric analysis. Quantification of grain sizes and orientations from SE images of rough surfaces requires difficult and time-consuming photogrammetric techniques (Huggett, 1982) and is hindered by a difficulty in

\footnotetext{
${ }^{1}$ Moore, J. C., Mascle, A., et al., 1990. Proc. ODP, Sci. Results, 110: College Station, TX (Ocean Drilling Program).

2 Department of Earth Sciences, Leeds University, Leeds LS2 9JT, United Kingdom.

${ }^{3}$ Institut für Geowissenschaften und Lithosphärenforschung, Universität Giessen, Senckenbergstrasse 3, D6300 Giessen, Federal Republic of Germany.
}

distinguishing individual phyllosilicates from aggregates. To prevent charging, rough-cut surfaces must be coated in a heavy metal (generally gold or platinum; Goldstein and Yakowitz, 1975) which, along with the uneven nature of the surface, prevents the use of image intensity to infer compositional differences and severely limits the effectiveness of X-ray microanalysis (Goldstein et al., 1981).

BSE images give superb contrast between grains of different composition (and under certain conditions, different crystal orientation), on flat, well-polished specimens (Lloyd and Hall, 1981; Lloyd, 1985; 1987), but the spatial resolution cannot match that of SE images because of the larger activation volume for backscattered electrons (Goldstein and Yakowitz, 1975). Published BSE images of fine-grained sedimentary material (Pye and Krinsley, 1983; Krinsley et al., 1983; White et al., 1984 ; 1985; Burton et al., 1987) show a resolution of $1 \mu \mathrm{m}$ at best and more generally a resolution of 2 or $3 \mu \mathrm{m}$. This resolution is of little use in examining clay mirofabric with an average grain size of $1 \mu \mathrm{m}$ or less; , however, these studies pay little attention to methods of specimen preparation and SEM operation that may improve resolution.

BSE images of hard rock specimens show that careful specimen preparation is crucial to the spatial resolution and phase contrast of BSE images (Lloyd, 1987) and the application of careful polishing methods (see Prior, 1988: Appendix lc) has given a resolution of $50 \mathrm{~nm}$ or better (G. E. Lloyd, unpublished data; D. J. Prior, unpublished data). The same polishing techniques, adapted for solvent-sensitive specimens such as the Leg 110 ODP sediments, combined with optimization of SEM operating conditions have increased the resolution of BSE images so that clay microfabric investigations are now possible. Here we present methods and preliminary results of our investigations in the hope that other researchers may adopt and help refine these techniques, and improve the data base for studies of diagenesis, anchizonal metamorphism, and fabric development in clay-rich specimens. 


\section{METHODS}

\section{Specimen Preparation}

Specimens were freeze dried and impregnated with a low-viscosity epoxy resin immediately after sampling of the core during the Leg 110 ODP cruise. Specimens were fractured in this process but the fabric and textures between the fractures have not been affected. Recent studies (Bennett and Hulbert, 1987) suggest that critical point drying methods give less likelihood of specimen damage during preparation.

Specimens were cut using a 0.5 -mm-thick diamond-coated saw blade and paraffin lubricant at cutting speeds of less than $10 \mu \mathrm{m} / \mathrm{s}$. Specimens were mounted in standard metallurgical epoxy disks of $25-\mathrm{mm}$ diameter (Fynn and Powell, 1979) and the examination surface carefully ground with 600 grade grit until all saw marks (only visible at high magnification in reflected light) were removed. Specimens were thoroughly cleansed in paraffin to remove all 600 grit before mechanical polishing.

Specimens were mechanically polished on a cloth-on-steel lap using Dialap diamond polishing compounds and fluid. Polish was applied sequentially using 9-, 3-, 1-, and $0.25-\mu \mathrm{m}$ diamond paste. Specimens and lap were throughly cleaned in paraffin between each grade. For most specimens this is as far as polishing could progress.

Very fine polishing can be achieved by chemical-mechanical polishing (Fynn and Powell, 1979; Lloyd, 1987). For this process we used a Malvern Instruments SYTON polisher in which polishing by chemical corrosion is effected by an $\mathrm{NaOH}$ solution and mechanical polishing by $100-\AA$ silica particles that form a colloid with the $\mathrm{NaOH}$. Best results are achieved by balancing the rates of chemical and mechanical polishing, the former controlled by the rate of fluid flow and the latter by the lap rotation rate (Fynn and Powell, 1979). For specimens that contained significant carbonate material this was possible, and a polish to better than $0.01 \mu \mathrm{m}$ was obtained after 8 to $12 \mathrm{hr}$ on the SYTON. After SYTON polishing, specimens were washed in ethanol and dried in a flow of warm air. Unfortunately carbonate-poor samples corroded much too fast, and the $0.25-\mu \mathrm{m}$ polish was irreparably destroyed after only 30 minutes on the SYTON. Consequently, carbonate-poor specimens have only been diamond polished to $0.25 \mu \mathrm{m}$.

\section{SEM Equipment and Operating Conditions}

Two SEMs have been used in the BSE studies presented here. Best results were obtained using a CAMSCAN Series 4 at working distances of $8 \mathrm{~mm}$ or less between specimen and backscatter detector and an accelerating voltage of $30 \mathrm{kV}$. The detector used was a four-quadrant, semiconductor, ring detector. Resolution is reduced drastically as working distance is increased. The smallest resolvable grain size at 14-mm working distance is three or four times larger than that at $7 \mathrm{~mm}$. This accounts for the poorer resolution of the second SEM used in this study, a CAMSCAN Series 2, which has a minimum working distance of $15 \mathrm{~mm}$. At $20 \mathrm{kV}$ the smallest resolvable grain size is twice that at $30 \mathrm{kV}$. This is difficult to understand as the activation volume should increase and the resolution decrease with increasing accelerating voltage (Goldstein and Yakowitz, 1975; Lloyd, 1985). A preliminary explanation is (G. E. Lloyd, pers. commun., 1988) that the beam is collimated by the numerous grain boundaries in fine-grained material so that the specimen is penetrated more deeply at high accelerating voltages, and the deeply penetrated electrons, which would reduce the resolution, cannot escape from the specimen. More recent work (unpublished data of S. M. Agar, G. E. Lloyd and D. J. Prior has shown that the optimum accelerating voltage for spatial resolution is specimen dependent. Some materials, particularly more crystalline specimens, give better results at very low accelerating voltages $(5-8 \mathrm{kV})$. Operating at a variety of accelerating voltages often allows examination of different depth (penetration) levels ain a single specimen. Generally it is better to work at accelerating voltages in excess of $15 \mathrm{kV}$ if the required resolution is possible, because routine imaging is much easier than at low accelerating voltages.

\section{ASSESSMENT OF PREPARATION DAMAGE}

During preparation, specimens come into contact with a number of solvents that may damage clay microfabric by hydration, glycolation, or similar processes (Huggett, 1982; Smart and Tovey, 1982; Bennett and Hulbert, 1987; Shaw, 1987). Care has been taken that specimens only contact paraffin and Dialap polishing fluid and, if SYTON polished, SYTON fluid and etha- nol. It is generally accepted that paraffin has no effect on clays (Smart and Tovey, 1982; Bennett and Hulbert, 1987) so specimens cut in paraffin have been used to experimentally assess the effect of the other solvents and also water and acetone, which may be alternatives in some preparation processes. Six 4-mm cubes were cut from one clay-rich Section 110-671B-58X-1. The specimens were mounted on stubs, carbon coated and examined by SE imagery. Each of five cubes was immersed for $24 \mathrm{hr}$ in one of the five solvents, air dried, gold coated, and re-examined on the SEM. The effects on impregnating epoxy, impregnated sediment, and unimpregnated sediment were noted and are shown in Table 1.

Water, SYTON, and acetone caused damage. The effects of water and SYTON are illustrated in Plate 1. The use of paraffin in cutting and grinding, rather than water, is justified. Acetone should be avoided as a cleaning agent. The effect of SYTON is dramatic yet it cannot be ruled out as a polishing compound, as the polishing process is intended to be partly corrosive. However, one must be wary in interpretation of microscopic features of successfully SYTON-polished specimens, because these may contain features induced by the chemical effects of the polishing.

\section{PRELIMINARY RESULTS}

\section{Spatial Resolution of BSE Images}

Calcareous specimens, which can be SYTON polished, give the best resolution. In addition, these specimens contain fairly large calcite fossils (Plates 2.1,2.2), with an intricate micrometer-scale internal structure that can be used to optimize the SEM operating and imaging conditions before moving into the specimen matrix (Plate 2.3). The resolution achieved in one calcareous Section, 110-671B-45X-3, is illustrated in Plate 3. A resolution of better than $100 \mathrm{~nm}$ is obtained (Plates $3.3,3.4$ ) and crisp images can be obtained at around $1000 \times$ magnification (Plates $2.3,3.1,3.2$ ). Each of the image areas shown was examined using SE to show that the specimen surface was flat. SE images were, however, of poor quality as the very thin carbon coating needed for BSE imaging (Lloyd, 1987) and the high accelerating voltage lead to charging problems. The dark backgrounds to the images (Plate 3 ) are a mixture of epoxy-filled pores and low backscatter intensity phases that are not resolvable at the BSE contrast settings used for these electron micrographs.

Clay-rich specimens cannot be SYTON polished, and less detail is resolvable. Nevertheless, images of one clay-rich Section 110-671B-58X-1, shown in Plate 4, give a resolution of 200 to $300 \mathrm{~nm}$. Again SE images show the specimen surfaces to be flat.

The lowest resolution achieved here is an order of magnitude better than earlier BSE images of soft sediments (Pye and Krinsley, 1983; Krinsley et al., 1983), and three to five times better than the best published results (White et al., 1984).

Table 1. The effects of varous solvents on sawn cubes of Section 110-671B-58X-1. The effects on impregnated and unimpregnated material and the impregnating epoxy have been distinguished.

\begin{tabular}{|c|c|c|c|}
\hline & $\begin{array}{c}\text { Effect on } \\
\text { impregnating } \\
\text { epoxy }\end{array}$ & $\begin{array}{l}\text { Effect on } \\
\text { impregnated } \\
\text { sediment }\end{array}$ & $\begin{array}{l}\text { Effect on } \\
\text { unimpregnated } \\
\text { sediment }\end{array}$ \\
\hline Water & None & Hairline fracutres & $\begin{array}{l}\text { Removal of most } \\
\text { material }\end{array}$ \\
\hline DIALAP & None & None & None \\
\hline SYSTON & None & $\begin{array}{l}\text { Removal of surface } \\
\text { material. Fracturing }\end{array}$ & $\begin{array}{l}\text { Removal of all } \\
\text { material }\end{array}$ \\
\hline Acetone & $\begin{array}{l}\text { Bubbles } \\
\text { develop }\end{array}$ & $\begin{array}{l}\text { Slight surface distur- } \\
\text { bance }\end{array}$ & None \\
\hline Ethanol & None & None & None \\
\hline
\end{tabular}




\section{Mineralogical and Textural Observations}

The fine-grained matrix of carbonate-rich Section 110-671B$45 \mathrm{X}-3$ comprises clasts of calcite, plagioclase (Anl0 approximately), quartz (not shown), and fossil fragments (calcite) in a clay matrix. Mineral identification can be made on the basis of backscatter intensities coupled with spot checks using energy dispersive (EDS) X-ray analysis. Fully quantitative microchemi$\mathrm{cal}$ analysis of most matrix grains is not possible because they are smaller than the X-ray fluorescence activation volume (Goldstein et al., 1981). There are three different phyllosilicate phases identified in Plates 2.3 and 3, on the basis of backscatter intensity. The largest phyllosilicates have EDS spectra indicative of an illitic composition with peaks for $\mathrm{K}, \mathrm{Na}, \mathrm{Fe}, \mathrm{Mg}, \mathrm{Si}$, and $\mathrm{Al}$. This is compatible with their backscatter intensity, which is similar to plagioclase, as predicted by calculations of backscatter intensity on the basis of mean atomic mass (White et al., 1984; Lloyd, 1987). The second phyllosilicate is finer than the illite, and has a darker backscatter intensity, suggesting it is kaolinite or montmorillonite (smectite). Na peaks, detected by EDS in this clay, suggest this is most likely to be Na-montmorillonite. The third phyllosilicate phase, about the same size as montmorillonite, is as bright as calcite and on the basis of its mean atomic number may be chlorite. Resolution is good enough to make observations on matrix clay microtextures. Illites appear as supportive struts between other matrix components (Plate 3.4), while montmorillonites are more often wrapped around clastic grains of the matrix, such as those around the plagioclase in Plate 3.3. The bending of some clays (e.g., Plate 3.4) may be a result of solvent damage during SYTON polishing and care must be taken in interpretation.

A typical clay-rich Section, 110-671B-58X-1, comprises clasts of plagioclase (An10 approximately), quartz and detrital phyllosilicate in a fine clay matrix (Plate 4). EDS suggests that the large, kinked phyllosilicate in Plates 4.1, 4.2 are a Fe-rich illite or white mica. Matrix clays are darker than the detrital phyllosilicate indicating that they are kaolinite or montmorillonite (smectite). EDS spectra from the matrix show no $\mathrm{Na}$ or $\mathrm{Ca}$ peaks, suggesting that kaolinite is more likely. $\mathrm{Fe}$ and $\mathrm{Mg}$ peaks are observed. These are thought to originate from fine bright phyllosilicate phases, probably chlorite. The kaolinite matrix has a hairy texture with little grain alignment.

The mineralogical interpretations outlined in this section are consistent with XRD data from the Barbados region (Schoonmaker, 1986; Schoonmaker et al., 1986), which generally indicate the presence of smectite, illite, and kaolinite/chlorite.

\section{Quantification of Clay Microfabric}

Selected areas from Section 110-671B-45X-3 have been used to illustrate the potential for detailed quantification of clay microfabrics and grain sizes. Orientations and sizes of grains are quantified using a digitizing tablet and TURBO pascal programs developed by Prior (1988). The long-axis lengths and orientations are recorded for clays. For clastic grains the grain shape is used to define the long-axis orientation and grain size is estimated as the diameter of a circle of equivalent area to any measured grain. Areas examined are shown in Plate 5. Three rectangular areas of about $15 \times 30 \mu \mathrm{m}$ were examined in a zone adjacent to brittly deformed, flattened fossils. Plates 5.2, 5.3, and 5.4 show the areas measured. The region encompassing these subareas is shown at lower magnification in Plate 5.1. A fourth area, inside a flattened fossil, was examined and is shown in Plates 5.5 and 5.6.

The sizes of all clasts and clays for all four measurement areas have been drawn up as frequency histograms of the root of grain size in Figure 1. There has been no stereological correction of grain-size magnitudes or distributions. The clast distribution

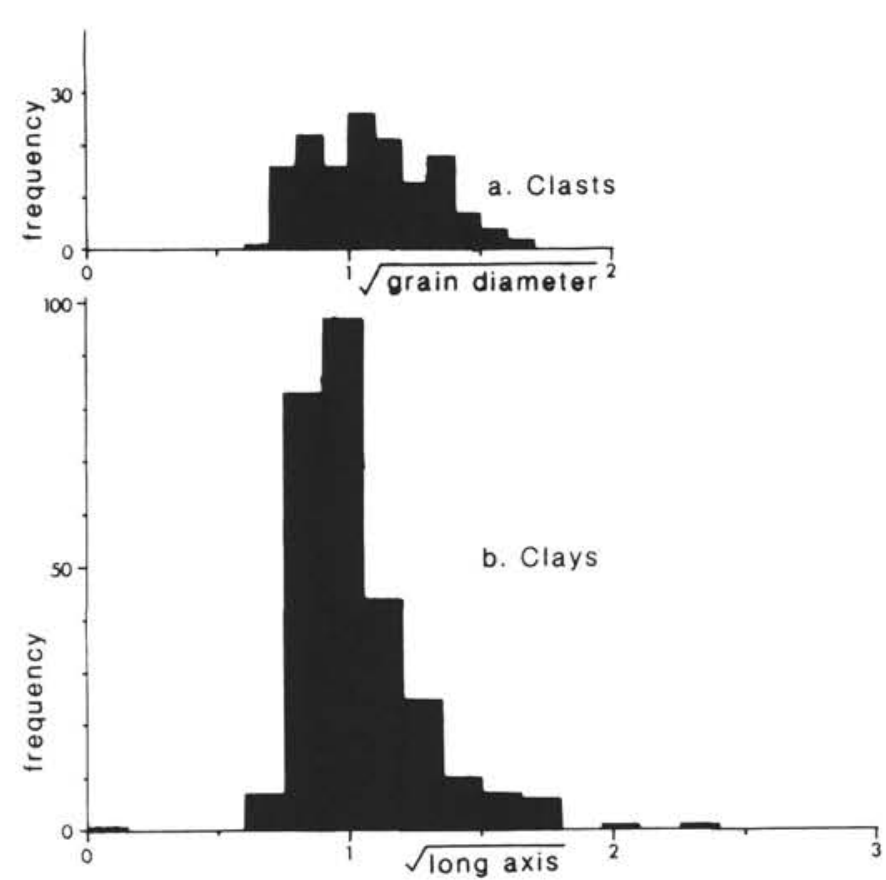

Figure 1. Frequency distributions of the root of grain sizes for clasts (a) and long axes for clays (b). Data for all four areas shown in Plate 5 are amalgamated in these histograms. Units are in $\mu \mathrm{m}^{0.5}$.

approximates to a root normal distribution, with a mean grain size of about $1.1 \mu \mathrm{m}$. The clay grain size is skewed by a tail of larger grain sizes, up to about $4 \mu \mathrm{m}$, superimposed on a normal distribution with a mean of about $0.8 \mu \mathrm{m}$. This relationship reflects the combination of more than one grain-size population, each related to a different clay phase and, perhaps illustrating microscopic porphyroblast-matrix relationships. In this example the larger grain sizes are mainly illite, while the finer grains are smectite. Future studies must distinguish the different clay phases in grain-size measurements.

Orientations of clays and clasts are shown in Figure 2. Figures $2 \mathrm{a}, 2 \mathrm{~b}, 2 \mathrm{c}$, and $2 \mathrm{~d}$ correspond to the areas shown in Plates $5.2,5.3,5.4$, and 5.6, respectively. The upper half of each rose shows clay orientations and the lower half, clasts. There is a good correspondence of the intensity and orientation of clast and clay fabrics in each area. These data illustrate that the fabric is defined by the microscopic alignment of all matrix components, and fabric intensity is controlled by local microstructure. For example, the fabric inside a flattened fossil (Plate 5.5) is more intense than that in the protected regions between less-deformed fossils (Plate 5.1). The fabrics shown in these images are probably related to sedimentary compaction.

\section{MICROFABRICS IN THE BASAL DÉCOLLEMENT ZONE}

Hole $671 \mathrm{~B}$ is unique in that it penetrates the basal décollement and the downgoing plate (Behrmann et al., 1988; Moore, Mascle, et al., 1987; 1988; Moore et al., 1988. The décollement zone was sampled between 500 and $550 \mathrm{~m}$ and is identified as a zone in which "scaly fabric" is strongly developed and fluid flow is indicated by a major anomaly in pore-fluid chemistry (Behrmann et al., 1988; Gieskes et al., in press; Moore, Mascle, et al., 1987; 1988; Moore et al., 1988). The décollement has a critical role in controlling the dewatering of accretionary complexes and in the transfer of stresses from the lower to the upper plate. Microstructural investigations in the décollement zone are important as these can constrain the deformation mechanisms 


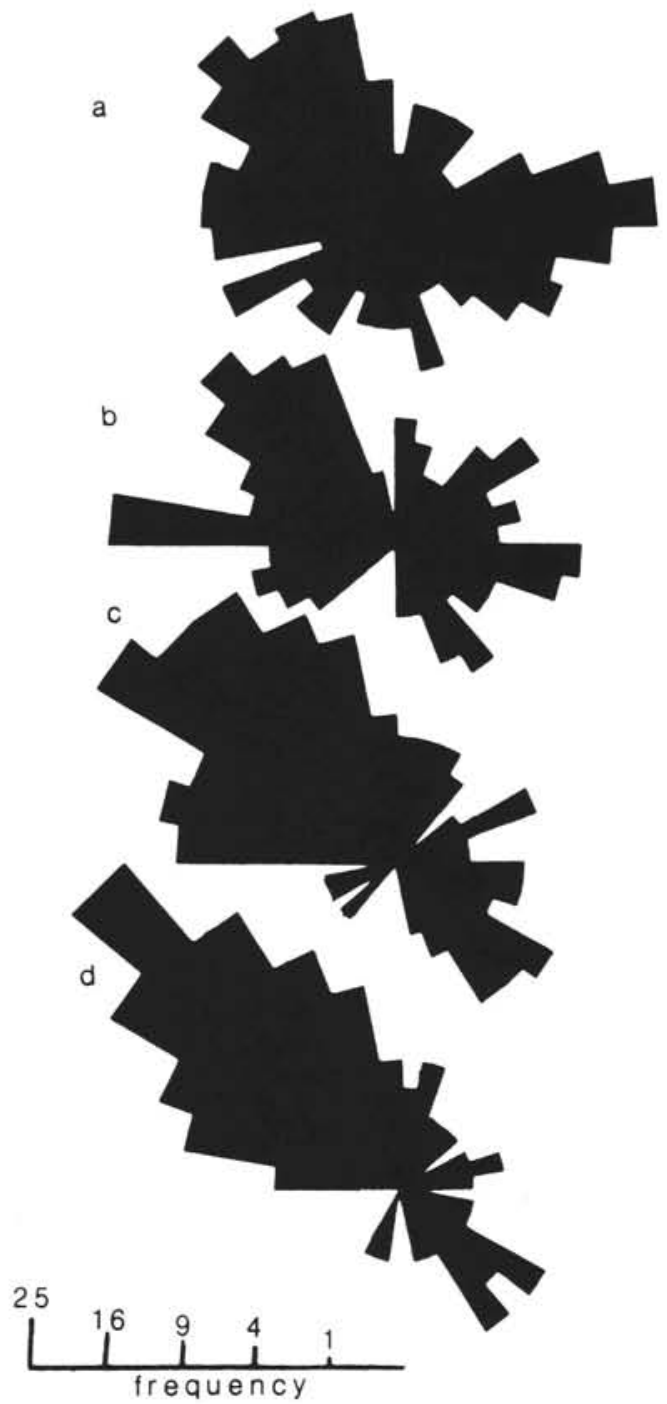

Figure 2. Rose diagrams showing orientations of clays and clasts for the four measurement areas shown in Plate 5. Figure $2 \mathrm{a}, \mathrm{b}, \mathrm{c}$ correspond to areas shown in Plates 5.2, 5.3, and 5.4. Figure 2d corresponds to the area shown in Plate 5.5. The upper half of each rose shows clay orientations and the lower half, clast orientations. The horizontal line in figure 2 corresponds to the horizontal in Plate 5.

operable in the décollement zone and through these the mechanical behavior. Deformation mechanisms studies, together with an analysis of overall microfabric, have an important bearing on the nature of fluid flow and permeability.

Plates 4 and 6 show the clay microfabrics typical of the décollement ooze and their relationship to "scaly fabric." The "scaly fabric" observed in the core is defined by irregular, subparallel, slightly anastamosing fracture surfaces. The microfabric on the grain-scale indicates a random assortment of phyllosilicate and clast orientations. There are two unexpected and initially alarming inferences of these BSE SEM data:

1. "Scaly Fabric" in the basal decollement of the Barbados forearc does not correspond to the grain-scale microfabric and we have to seek an alternative explanation for its origin. "Scaly fabric" is often uncharacteristic of grain-scale microfabrics in fine-grained sediments (Agar et al., unpublished data; Agar and Prior, unpublished data) although both "Scaly fabrics" and microfabrics may result from a variety of mechanisms. In the ba- sal décollement zone sampled in Hole 671B the "scaly fabric" undoubtedly postdates the microfabric. It is doubtful that the fracturing associated with "scaly fabrics" contributed significantly to the finite strain accumulated by the muds of the basal décollement without modification of the clay microstructure at fracture margins. If not finite strain-dependent microstructures, "scaly fabrics" may relate to principal stress orientations. We speculate that "scaly fabric" developed during core recorcery due to the release of in-situ stresses. In this case the greatest compressive stress is oriented normal to scaly surfaces.

2. Small-scale structures indicate that there has been major deformation in the décollement zone material sampled in Hole 671B (Brown and Behrmann, this volume). This deformation must have been acommodated by a mechanism that does not develop a preferred alignment of grains. The only possible mechanism is one of independent particulate flow (e.g., Borradaile, 1981) under high pore fluid pressure conditions.

\section{POTENTIAL OF BSE INVESTIGATIONS: FUTURE PERSPECTIVES}

BSE techniques can be used to image the fine-grained clay matrix of sediments. The resolution obtainable is good enough to allow mineralogical and microtextural investigations. The sizes and shapes of clays and other matrix grains are clearly resolvable and can be quantified. BSE resolution is not sufficient to image grain boundary microstructures or deformation substructures of these matrix clays. For this work TEM is essential (e.g., Smart and Tovey, 1982; Knipe, 1986).

There are some immediate problems to be attacked using quantitative analysis of BSE images. These investigations yield information on how microfabric is constructed within an individual specimen and how it varies within that specimen. The data from the décollement zone illustrates the type of investigations that can be conducted. The data described provides an unexpected contradiction of the perceived view of décollement microstructure: that the scaly fabric represents anastamosing zones of phyllosilicate alignment resulting from the shearing of clays. Further studies on the interrelationsips of deformation and fluid processes in accretionary prisms, both on land and as sampled in ODP Legs must include detailed microstructural studies on the grain-scale of sediments involved. For fine-grained material this will invariably require electron microscopy and we suggest that BSE SEM is the most versatile routinely applicable tool for these studies.

\section{ACKNOWLEDGMENTS}

Kevin Rogers (aboard JOIDES Resolution), Geoff Lloyd, Tony Nichells, and John Harrington are thanked for their help and advice in specimen preparation and SEM operation. Manuscript reviews by Sue Agar, Geoff Lloyd, Joe Mcquaker and Casey Moore are gratefully acknowledged. This research was funded by Deutsche Forschungsgemeinschaft (Grant No. BelO4l/2-1 to JHB).

\section{REFERENCES}

Behrmann, J. H., Brown, K., Moore, J. C., Mascle, A., Taylor, E., et al., 1988. Evolution of structures and fabrics in the Barbados Accretionary Prism. Insights from Leg 110 of the Ocean Drilling Program. J. Struct. Geol., 10:577-592.

Bennett, R. H. and Hulbert, M. H., 1987. Clay Microstructure: Boston (IHRDC Publ.).

Brown, K. M., and Westbrook, G. K., 1987. The tectonic fabric of the Barbados Ridge Accretionary Complex. Mar. Pet. Geol., 4:71-81.

Burton, J. H., Krinsley, D. H., and Pye, K., 1987. Authigenesis of kaolinite and chlorite in Texas gulf coast sediments. Clays Clay Miner, 35:291-296.

Fynn, G. W., and Powell, W.J.A., 1979. The Cutting and Polishing of Electro-optic Materials: London (Adams-Hilger).

Gieskes, J., Blanc, G., Vrolijk, P., Moore, J. C., Mascle, A., Taylor, E., Andreieff, P., Alvarez, F., Barnes, R., Beck, C., Behrmann, J., 
Brown, K., Clark, M., Dolan, J., Fisher, A., Hounslow, M., McClellan, P., Moran, K., Ogawa, Y., Sakai, T, Schoonmaker, J., Wilkens, R., and Williams, C., in press. Hydrogeochemistry in the Barbados Accretionary Complex. Tectonophysics.

Goldstein, J. I., Newbury, D. E., Echlin, P., Joyce, D. C., Fiori, C., and Lifshin, E., 1981. Scanning Electron Microscopy and X-ray Microanalysis: New York (Plenum).

Goldstein, J. I., and Yakowitz, H., 1975. Practical Scanning Electron Microscopy: New York (Plenum).

Huggett, J. M., 1982. The growth and origin of authigenic clay minerals in sandstones [Ph.D. dissert.]. Univ. of London.

Knipe, R. J., 1986. Microstructural evolution of vein arrays preserved in Deep Sea Drilling Project cores from the Japan Trench, Leg 57. Geol. Soc. Am. Mem., 166:75-87.

Krinsley, D. H., Pye, K., and Kearsley, A. T., 1983. Application of backscattered electron microscopy in shale petrology. Geol. Mag., 120:109-114.

Lloyd, G. E., 1985. Review of instrumentation, techniques and applications of SEM in mineralogy. In White, J. C. (Ed.), Applications of electron microscopy in earth sciences: Miner. Assoc. Canada, Short Course, 11:155-188.

1987. Atomic number and crystallographic contrast images with the SEM: a review of backscattered techniques. Mineral. Mag., 51:3-19.

Lloyd, G. E., and Hall, M. G., 1981. Application of scanning electron microscopy to the study of deformed rocks. Tectonophysics, 78:687698.

ODP Leg 110 Scientific Party, 1987. Expulsion of fluids from depth along a subduction-zone decollement horizon. Nature, 326:785-788.

Moore, J. C., Roeske, S., Lundberg, N., Schoonmaker, J., Cowan, D. S., Gonzales, E., and Lucas, S. E., 1986. Scaly fabrics from Deep
Sea Drilling Project cores from Deep Sea Drilling Project cores from forearcs. Geol. Soc. Am. Mem., 166: 55-73.

Potter, P. E., Maynard, J. B., and Pryor, W. A., 1980. Sedimentology of shale: Berlin (Springer).

Prior, D. J., 1988. Deformation processes in the Alpine Fault mylonites, South Island, New Zealand [Ph.D. dissert.]. Univ. of Leeds, U.K..

Pye, K., and Krinsley, D. H., 1983. Mudrocks examined by backscattered electron microscopy. Nature, 301:412-413.

Schoonmaker, J., 1986. Clay mineralogy and diagenesis of sediments from deformation zones in the Barbados Accretionary Wedge (DSDP Leg 78A). In Moore, J. C. (Ed.), Structural fabrics in Deep Sea Drilling Project cores from forearcs. Geol. Soc. Am. Mem., 166: 105-116.

Schoonmaker, J, MacKenzie, F. T., and Speed, R. C., 1986. Tectonic implications of illite/smectite diagenesis, Barbados Accretioary Prism. Clays Clay Miner., 34:4-9.

Shaw, H., 1987. Clays and their effects in source and reservoir rocks. JAPEC Course Notes, Geol. Soc. London.

Smart, P., and Tovey, K., 1982. Electron microscopy of soils and sediments: Techniques: Oxford (Oxford Univ. Press).

White, S. H., Huggett, J. M., and Shaw, H. F., 1985. Electron optical studies of phyllosilicate intergrowths in sedimentary and metamorphic rocks. Mineral. Mag., 49:413-423.

White, S. H., Shaw, H. F., and Huggett, J. M., 1984. The use of backscattered electron imaging for the petrographic study of sandstones and shales. J. Sediment. Petrol., 54:487-494.

Date of initial receipt: 11 April 1988

Date of acceptance: 10 March 1989

Ms 110B-142 


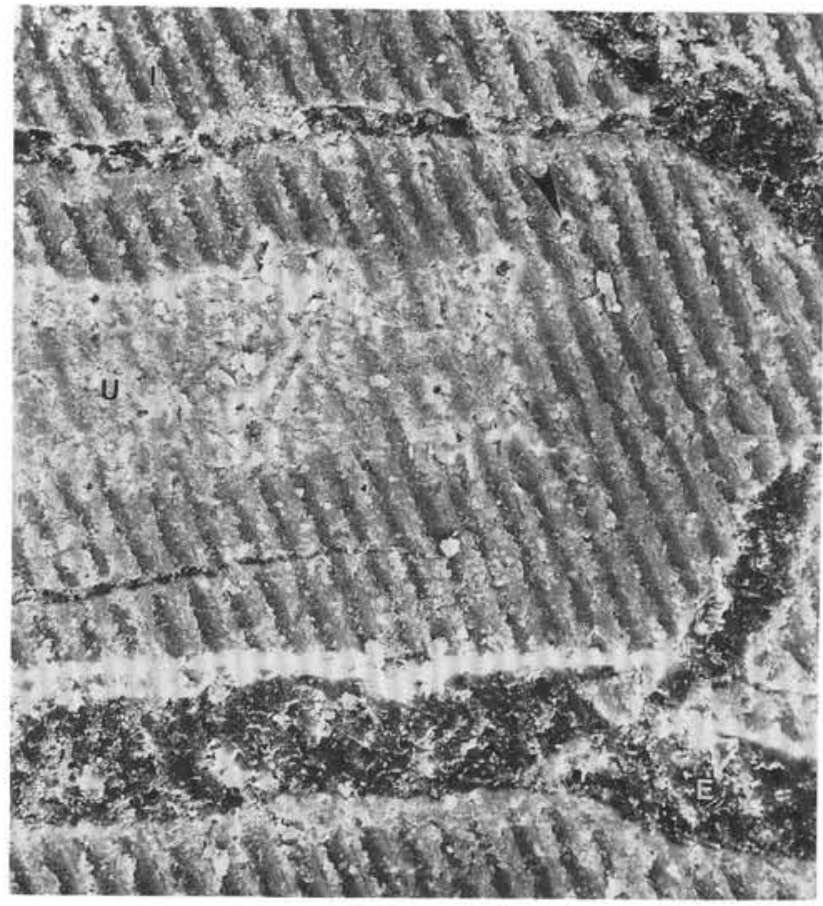

1

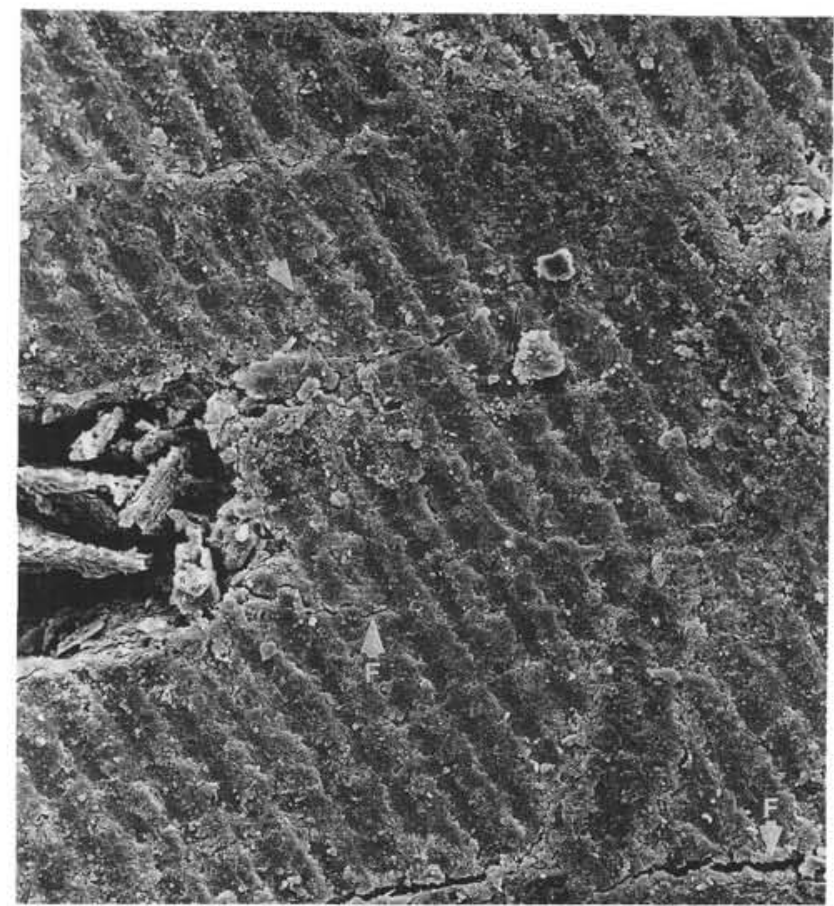

2

$50 \mu \mathrm{m}$

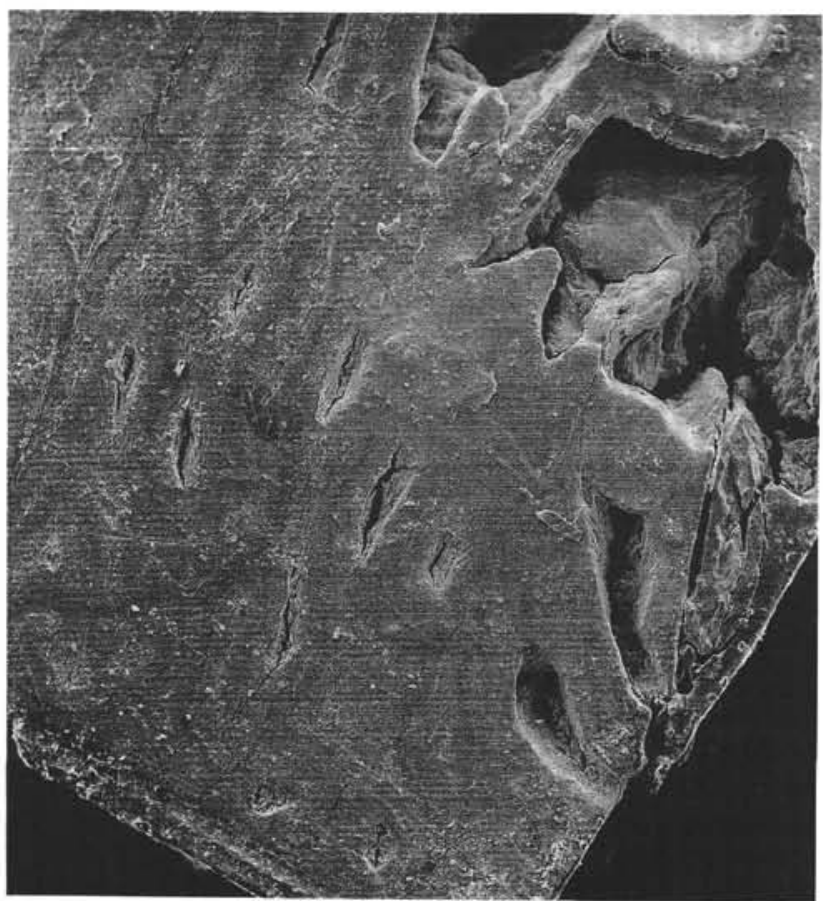

3

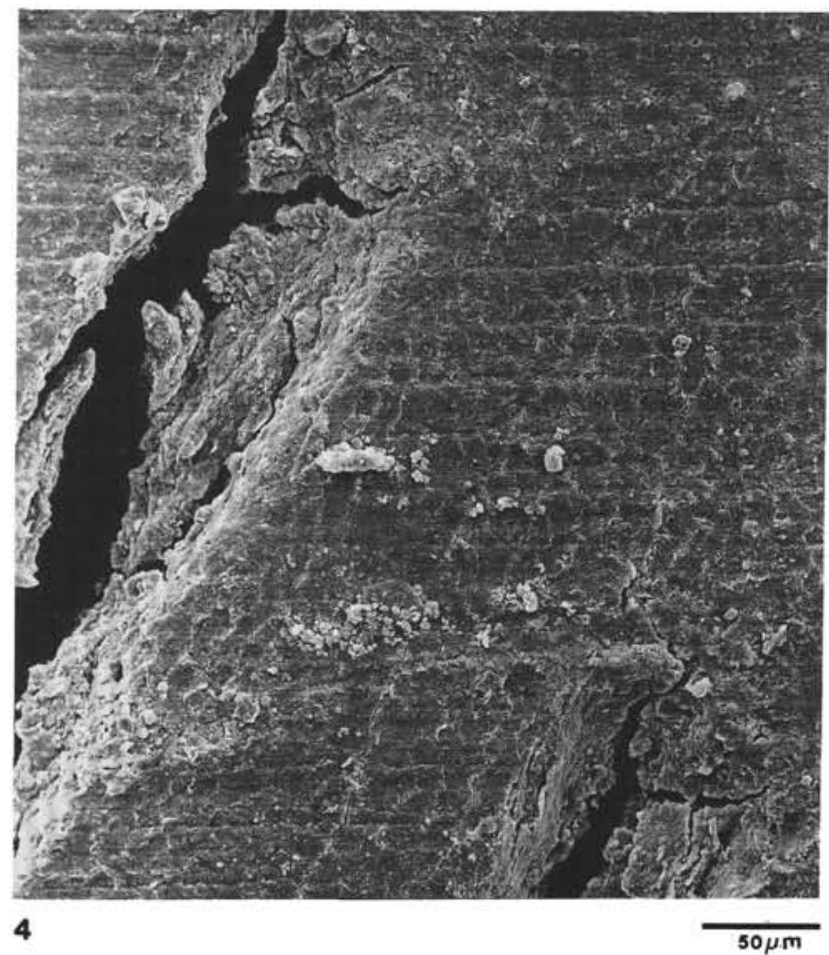

Plate 1. Tests of the effects of solvents used in specimen preparation. SE images are shown with a working distance of $10 \mathrm{~mm}$. (a) is taken at $25 \mathrm{kV}$ and the specimen is carbon coated. All other images are taken at $15 \mathrm{kV}$ using gold coatings. 1 . Specimen prior to solvent treatment. $\mathrm{E}=$ epoxyfilled fractures. $\mathrm{I}=$ regions of epoxy-impregnated sediment with prominent saw markings. $\mathrm{U}=$ regions where epoxy impregnation has not penetrated, with poorly developed saw marks and irregular surfaces. 2. Same area as 1 . after $24 \mathrm{hr}$ in tap water. Arrows show same point in 1 and 2 . The unimpregnated area is extensively corroded. Impregnated specimen is affected by a new set of fractures (one is marked F). Fractures are most common at boundaries with epoxy, and radiating from unimpregnated zones. 3. A different piece of the same specimen after $24 \mathrm{hr}$ in SYTON fluid. The specimen was so strongly affected that the area examined prior to treatment could not be recognised and located. Unimpregnated areas are totally removed. Impregnated material on the left of the image has an undulatory surface morphology caused by the solvent. 4. Close-up of the center of 3. Impregnated specimen is fractured and the saw markings have been dulled by removal of the ends of saw "ridges." 

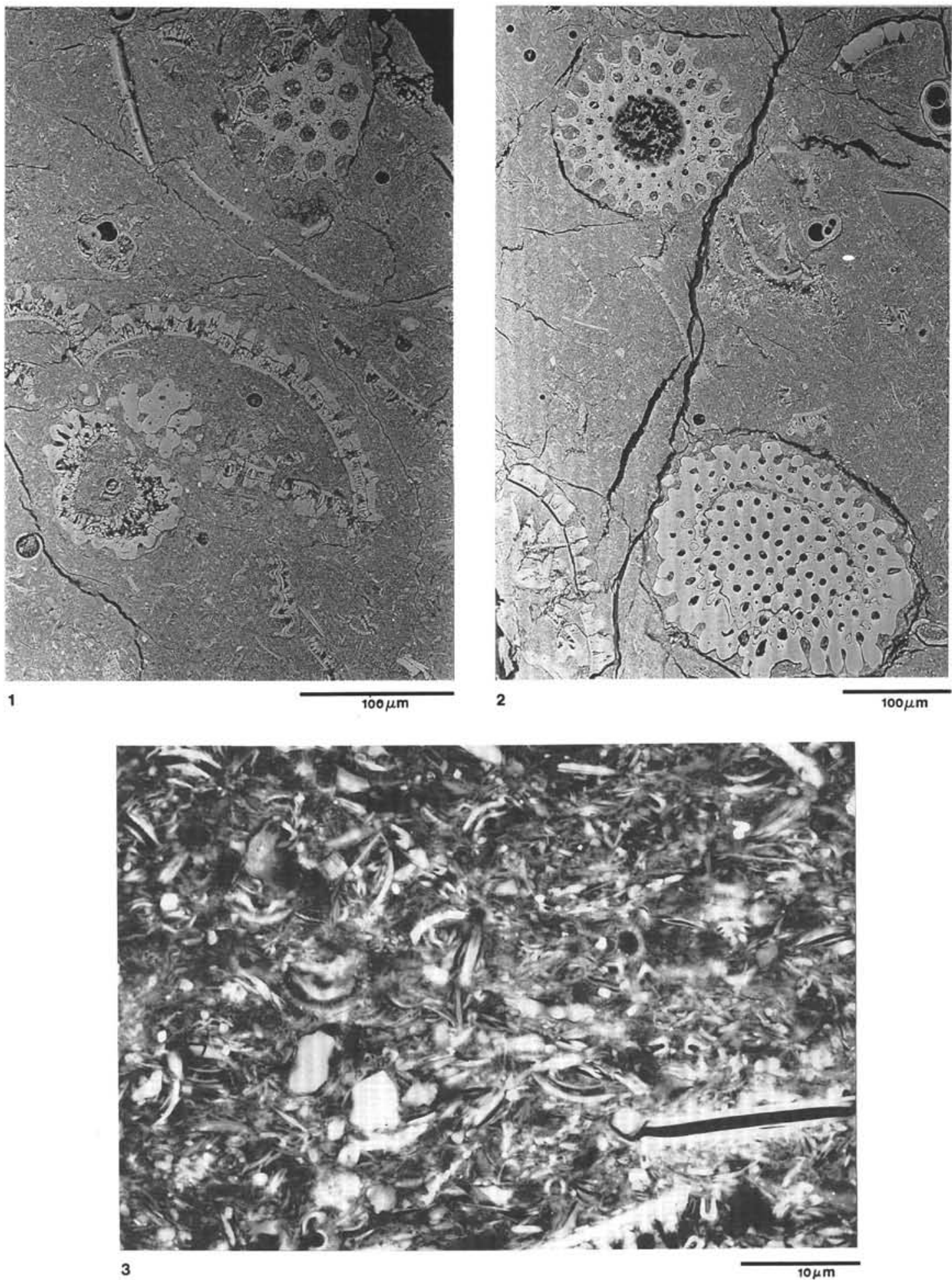

Plate 2. Section 110-671B-45X-3. 1, 2. Fossils greater than 20 or $30 \mu \mathrm{m}$ in size polish very well and can be used to optimize the imaging system on the SEM. These micrographs are taken on the CAMSCAN Series 2 at 16-mm working distance using $25-\mathrm{kV}$ accelerating voltage. 3. The specimen matrix comprises clasts of calcite and plagioclase, fragments of fossils and fine-grained clays. CAMSCAN Series 4 at 7-mm working distance and 30 $\mathrm{kV}$ accelerating voltage. 


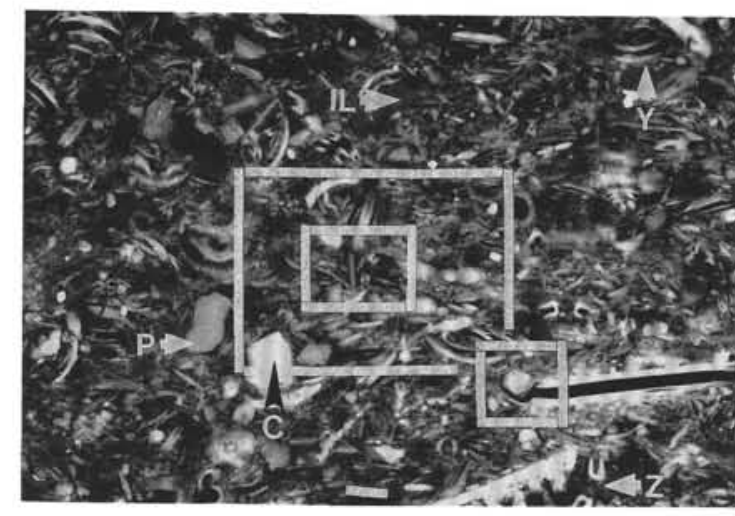

1

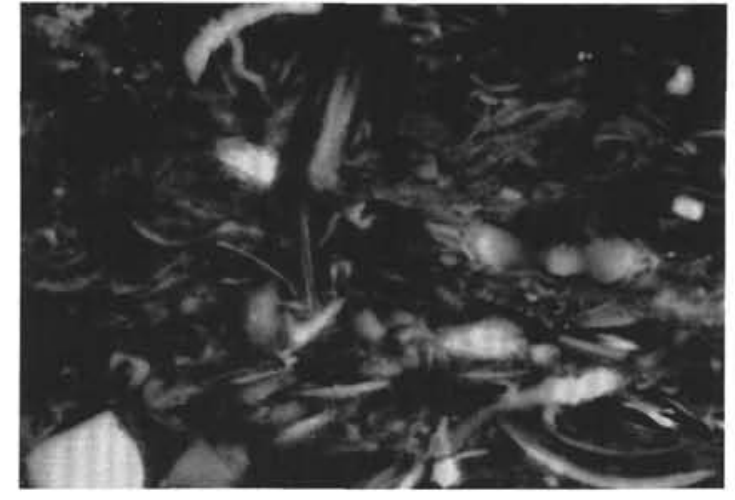

2

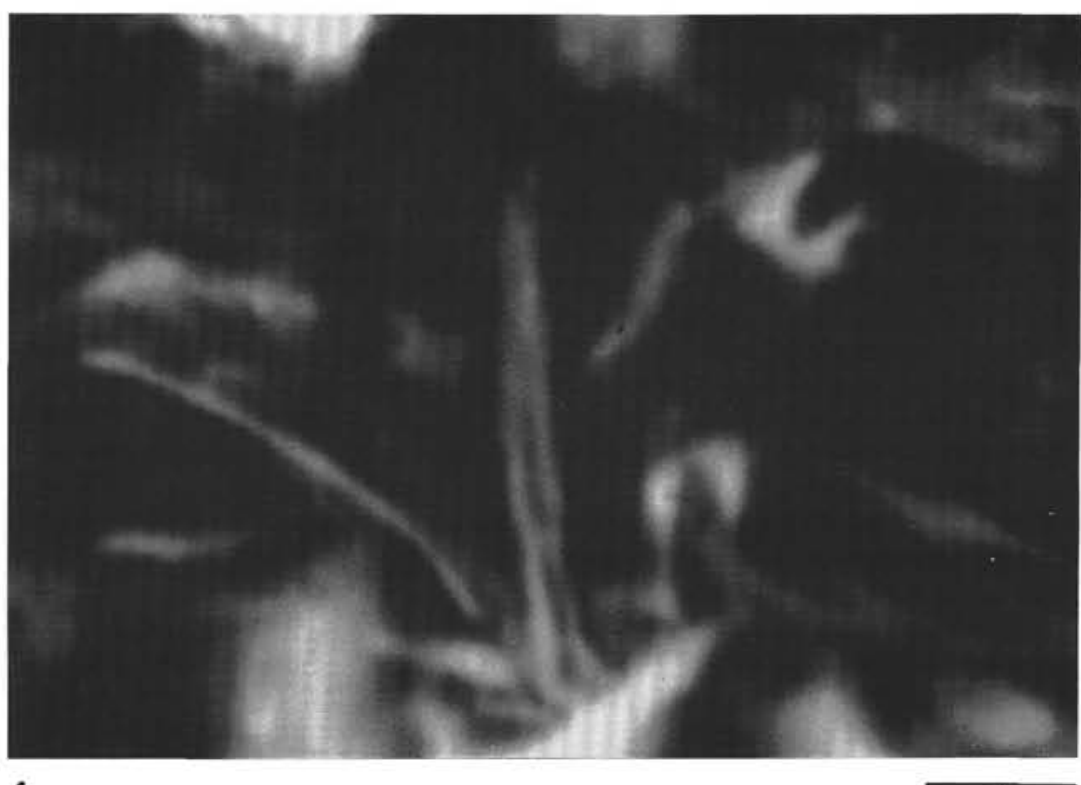

4

$1 \mu \mathrm{m}$

Plate 3. BSE images of Section 110-671B-45X-3 illustrating the resolution obtainable where SYTON polishing is possible and showing the components of the specimen matrix. All micrographs are taken on the CAMSCAN Series 4 using a working distance of $7 \mathrm{~mm}$ and an accelerating voltage of $30 \mathrm{kV}$. 1. View to show location of 2,3 , and 4. This image is shown unlabeled and at larger size in Plate 5.3. The matrix comprises plagioclase clasts (P), calcite clasts (C), clay material (IL)-The clays comprise illite, with the same backscatter intensity as plagioclase, and darker material that is probably Na montmorillonite (see text). There are also some small bright phyllosilicates that may be chlorite. There are many fine calcite clasts of obvious organic derivation. Two common examples include twin curved plates of calcite (Y) and pairs of calcite "claws", (Z). 2. Close-up of central portion of 1 . Note that the clays tend to form supportive struts between the other matrix components. 3. Clast of plagioclase at the end of a "twin plate" fossil relic (bright horizontal clasts on the right). Fine pale gray clays are wrapped around the plagioclase clast. These clays are darker than the plagioclase and may be Na montmorillonites. 4. Close-up of matrix illite clays acting as supportive material between other matrix components. The slight bending of clays may be due to hydration damage in polishing. 


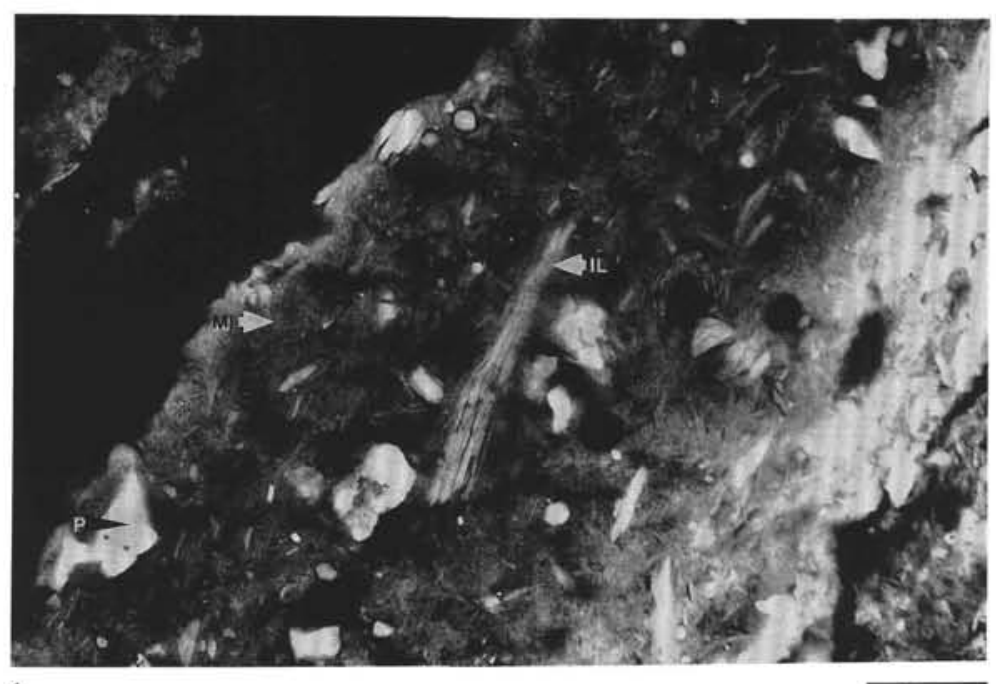

$10 \mu$
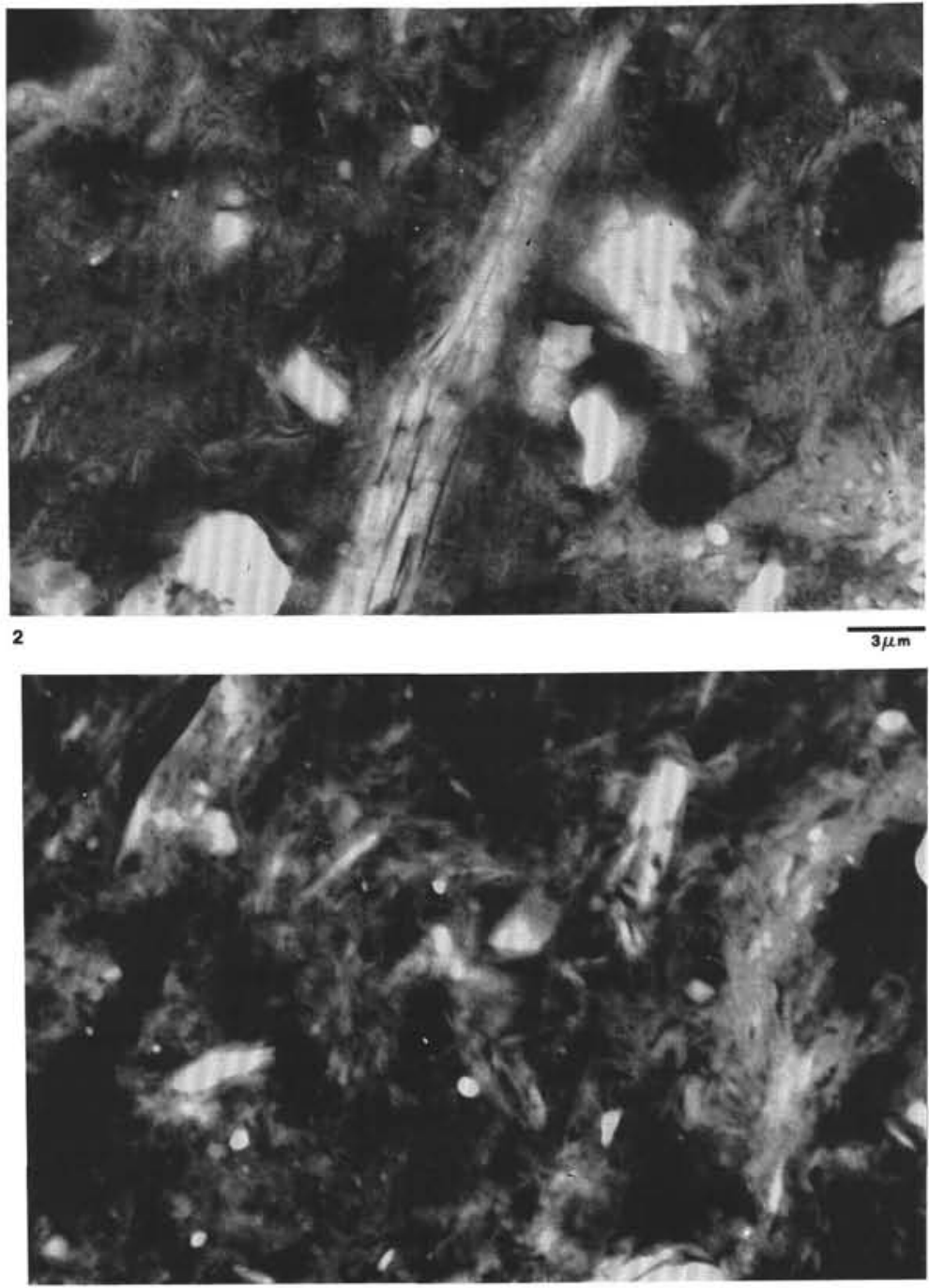

$3 \mu \mathrm{m}$

Plate 4. BSE images of clay-rich Section 110-671B-58X-1, which cannot be SYTON polished because of corrosion problems. This specimen has been mechanically polished to $0.25 \mu \mathrm{m}$. All micrographs are taken on a CAMSCAN Series 4 with a working distance of $7 \mathrm{~mm}$ and an accelerating voltage of $30 \mathrm{kV}$. 1. Dark band on the top left is an epoxy-filled fracture. Rather pale material on the right is poorly impregnated. Impregnated material comprises plagioclase clasts (P), a large detrital phyllosilicate (IL), and a fine-grained matrix of dark clay, probably kaolinite (MI), and some bright phyllosilicates that may be chlorite. 2. Close up of 1.3. Another area of the same specimen showing the clay matrix in more detail. 


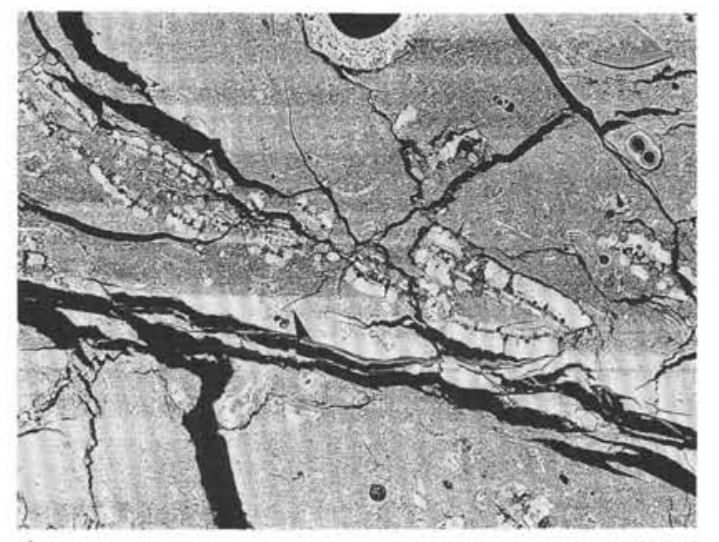

1

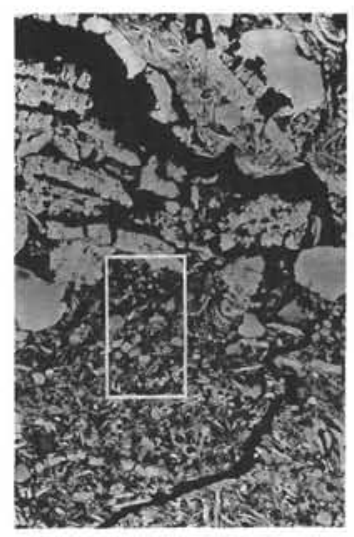

2

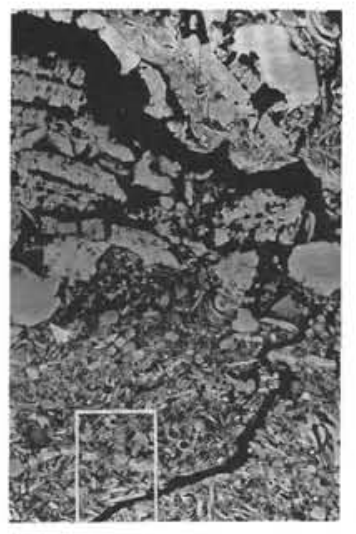

$\overline{\text { 10um }} 4$

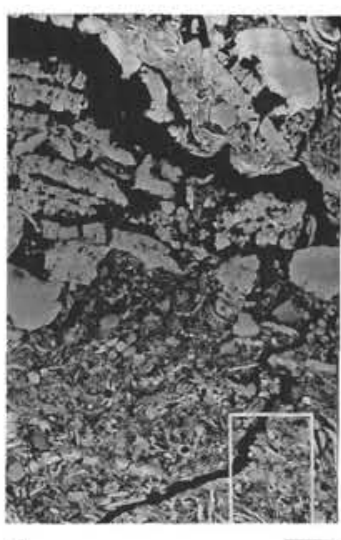

$\overline{10 \mu m}$
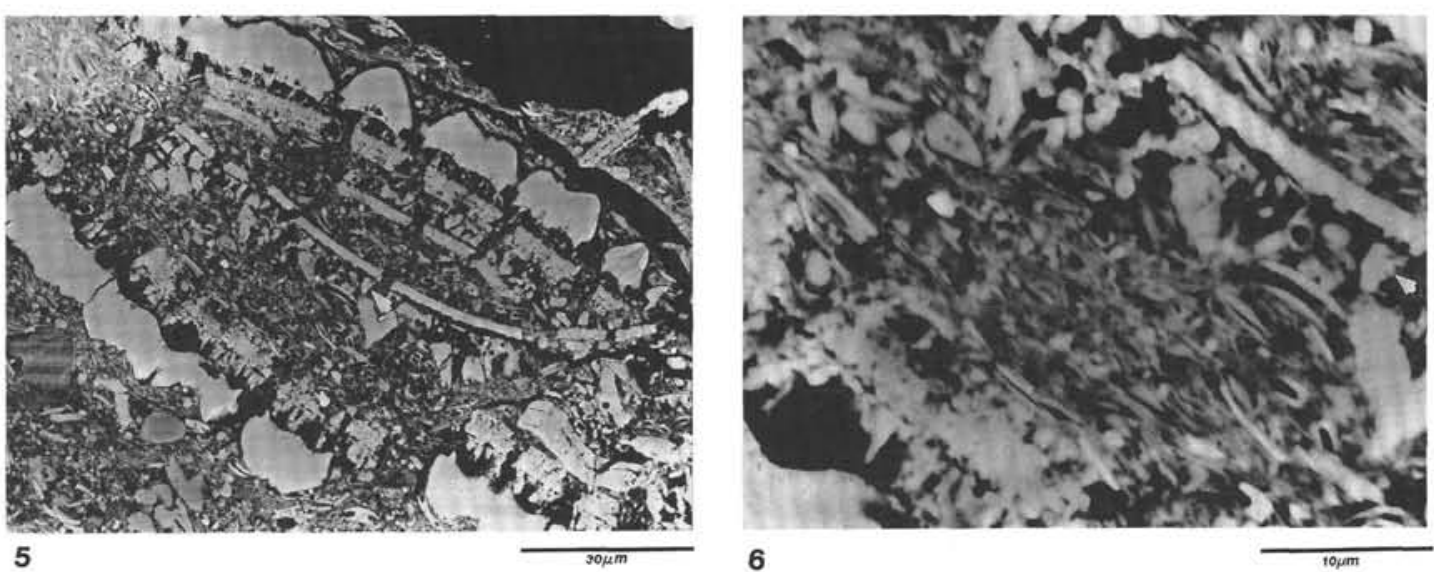

Plate 5. Areas used for quantitative clay and clast size/orientation analysis. Note the diagonal band of fractured, flattened fossils. 1. Low-magnification view of area examined. 2, 3, 4. Areas examined close to flattenned fossils are delineated by white boxes, arrow in 3 . corrrsponds to the arrow in 1. 5. View of area inside of a fossil. Area in which measurements are made is shown in 6. 


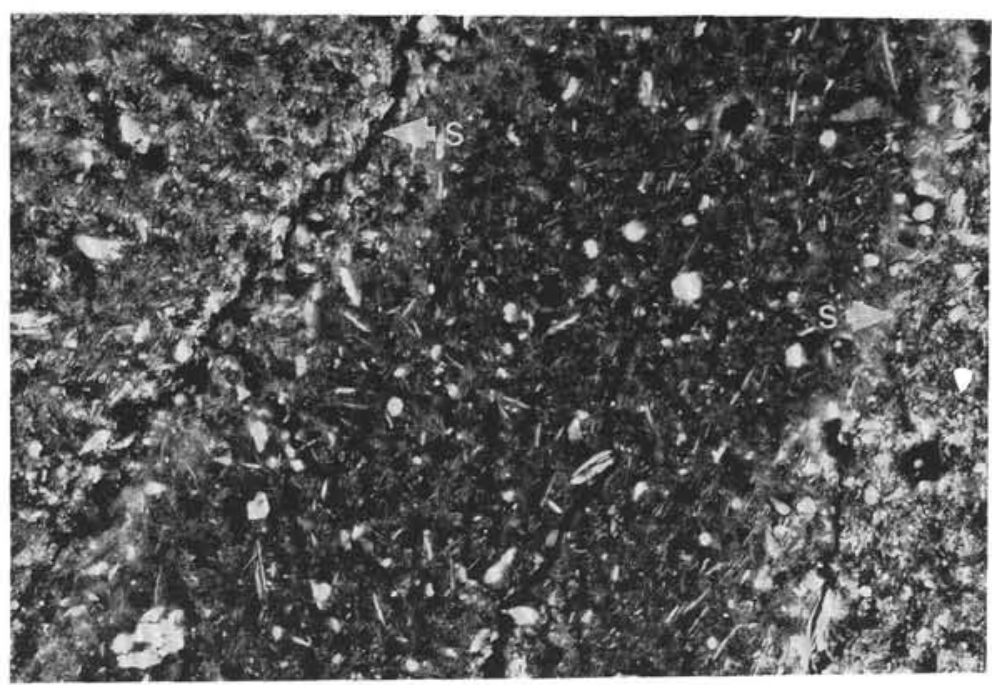

1

$30 \mu \mathrm{m}$

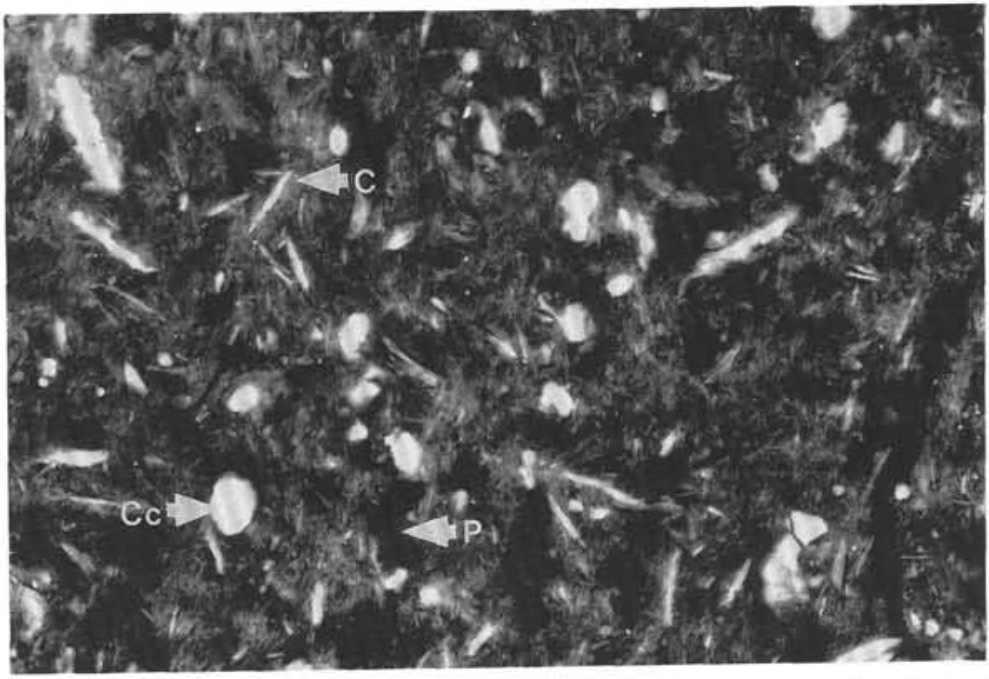

2

$10 \mu \mathrm{m}$

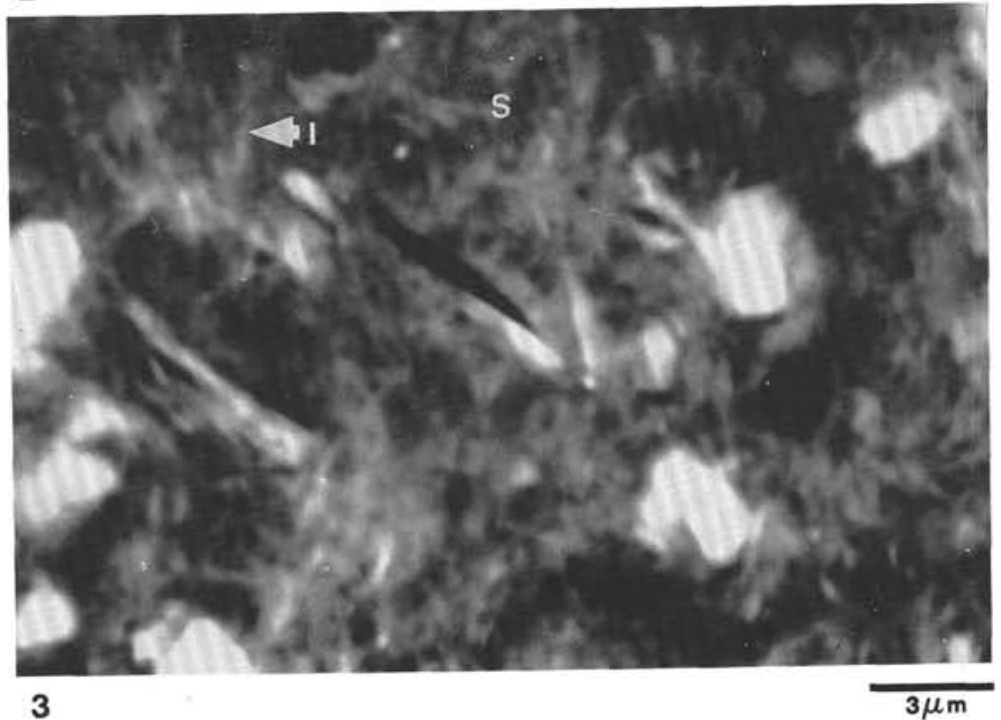

Plate 6. BSE micrographs from the décollement zone of the Barbados forearc. 1, 2, 3 are a sequence of increasing magnification from Section 110671B-59X-CC, taken on a Camscan Series 4 at $7-\mathrm{mm}$ working distance and $30-\mathrm{kV}$ accelerating voltage. 1. Lowest magnification image illustrates the relationship of the microfabric to the mesoscopic "scaly fabric" of the décollement, defined by fractures (S). 2, 3. Higher magnification images showing the nature of the microfabric. This comprises unaligned clasts of calcite $(\mathrm{Cc})$ and detrital chlorite $(\mathrm{C})$ in a "hairy" matrix predominantly of smectite (S) with some brighter grains of illite (I). Black areas (P) are pore space. 